\title{
ADAPTATION OF THE STUDENTS' MOTIVATION TOWARDS SCIENCE LEARNING QUESTIONNAIRE TO MEASURE GREEK STUDENTS' MOTIVATION TOWARDS BIOLOGY LEARNING
}

\author{
Helen Andressa ${ }^{1}$, Evangelia Mavrikaki ${ }^{2}$, Irini Dermitzaki ${ }^{3}$ \\ ${ }^{1}$ B.Sc., M.Sc., Biologist \\ ${ }^{2}$ National and Kapodistrian University of Athens, Assistant Professor, School of \\ Education, Faculty of Primary Education, Department of Science, Technology and \\ Environment, Athens, Greece, \\ Email: emavrikaki@primedu.uoa.gr \\ ${ }^{3}$ University of Thessaly, Associate Professor, Department of Early Childhood \\ Education, Volos, Greece
}

\section{Abstract}

The purpose of this study was to investigate students' motivation towards biology learning and to determine the factors that are related to it: students' gender and their parents' occupation (relevant with biology or not) were investigated. The sample of the study consisted of 360 Greek high school students of the $10^{\text {th }}$ grade (178 boys and 182 girls). The data were collected through Students' Motivation Toward Science Learning (SMTSL) questionnaire. It was found that it was a valid and reliable tool for Greek students, with 6 sub-scales: self-efficacy, biology learning value, active learning strategies, performance goal, achievement goal and learning environment stimulation. The results of the data analysis revealed that Greek students have a moderate level of motivation towards biology learning and no statistically significant differences were found between the two genders. A significant difference between scores obtained from the 'performance goal' factor of the SMTBL, in favor of female students, was revealed. Moreover, it was found that students' parents' occupation does not have an effect on students' motivation. All sub factors of the SMTBL scale were correlated except 'biology learning value' with 'performance goal'.

Key words: students' motivation, biology learning, parents' occupation, gender 


\section{Introduction}

Students' motivation plays an important role in the processes of conceptual change, critical thinking, learning strategies and achievements in learning science (Tuan, Chin, \& Shieh 2005). Motivation towards learning science is defined as an internal condition that stimulates, directs and maintains an attitude of learning science (Glynn, Brickman, Armstrong, \& Taasoobshirazi 2011). Most teachers believe that motivation is essential for effective learning. Many of them know that there are many ways to motivate students and all of them want the students to be motivated to learn and be involved in the learning process (Ainley 2004).

Students' motivation towards science is considered important for the decisions that students will make during their school life, ranging from the courses that they will attend to the profession that they will choose (Koul, Lerdpornkulrat, \& Chantara 2011; MamlokNaaman 2011). However, measuring students' motivation towards science constitutes a challenge, as the construct and its components are latent variables. Among the instruments that have been constructed to measure students' motivation towards science are:

- $\quad$ the Science Motivation Questionnaire (SMQ) (Glynn, Taasoobshirazi, \& Brickman 2009) which was used to assess undergraduate non-science students' motivation,

- the Students' Adaptive Learning Engagement in science (SALES) (Velayutham, Aldridge, \& Fraser 2011) which is suggested for lower secondary students and

- the Students' Motivation Toward Science Learning (SMTSL) (Tuan, Chin \& Shieh 2005) which was used to assess junior high school students. The researchers concluded that there are six factors of motivation that the instrument should be measuring: selfefficacy, active-learning strategies, science learning value, performance goal, achievement goal and learning environment stimulation.

Therefore, the purpose of our research is to construct a valid and reliable instrument that would measure students' motivation towards biology and then use this to measure Greek students' motivation.

\section{Factors associated with Students' Motivation towards Science}

\section{Learning}

Literature supports the idea that there are many factors that affect students' motivation towards science learning and some of them may be controlled by the teacher (e.g. the 
atmosphere in the classroom, the school environment, the teaching methods and the relevance of the course material to the everyday life of the student) and some of them not (e.g. home life and parental influence) (Cavaş 2011; Palmer 2005; Sevinç, Özmen, \& Yiğit 2011).

There are many studies (Sevinç, Özmen and Yiğit 2011; Tuan, Chin and Tsai 2003; Zeyer 2010) focusing on how students' motivation is affected by variables such as gender, academic achievement, parents' educational level, whether students attend special private courses and laboratory activities. They suggest that there are significant differences in students' motivation according to their gender, their academic achievement and whether they attend private courses or not. Laboratory activities, cooperation between students, relevance of science content to students' everyday life, praise from the teacher and the feeling of freedom to express their opinions without being criticized are factors that seem to positively influence students' motivation towards Science.

Several researchers have highlighted the importance of investigating students' motivation in different fields of science (i.e. biology, chemistry, physics) (Araoye, 2013; Baser 2007; Shihusa \& Keraro 2009) and in different ethnic groups (Linnenbrink \& Pintrich 2002). Dermitzaki, Stavroussi, Vavougios and Kotsis (2012) adapted the SMTSL questionnaire developed by Tuan, Chin and Shieh (2005) to the Greek language with a focus on physics learning, their target population undergraduate students. Dermitzaki et al. (2012) confirmed that the SMTSL questionnaire, adapted to Greek, has construct validity and an acceptable internal consistency (Cronbach's $\alpha$ from .68 to .85 for the subscales) but they pointed out the need for further testing and adaptation.

The aim of the present study was to reveal Greek high school students' motivation towards Biology learning and also find whether there are differences in students' motivation towards Biology relating to their parents' occupation and students' gender. For this purpose, we also chose to adapt the SMTSL questionnaire, as we considered it the most appropriate for the population under study (junior high school students) among the other instruments presented above.

\section{The role of gender on students' motivation towards Biology learning}

There are many studies focusing on the role that students' gender plays on their motivation towards learning science (Wigfield, Battle, Keller \& Eccles 2002) but less about male and 
female students' motivation towards learning biology. The existing literature on the subject is contradictory. Most researchers find girls to be more interested than boys in biology. Keeves and Kotte (1992) found that biology was the only science course in which more girls than boys were enrolled although these differences were not statistically significant. Dawson (2000) found that girls in Australia have a higher interest in biology topics than boys and the same was found by Prokop, Tuncer and Chuda (2007) about Slovakian girls. On the contrary, Shihusa and Keraro (2009) found that in Kenya boys' interest in biology is higher than girls'. In Greece, Mavrikaki, Koumparou, Kyriakoudi, Papacharalampous and Trimandili (2012) found that biology is equally popular with boys and girls.

\section{The role of parents' occupation on students' motivation towards Biology learning}

Parents' occupation is considered by some researchers as an important factor affecting students' motivation. Barak, Ashkar and Dori (2011) analyzed the effect of parents' occupation (whether relating to science or not) on students' motivation to learn science and found there were no statistically significant differences between the two groups. Krogh and Thomsen (2005) examined parents' occupation in their study of Danish students' attitudes towards physics.

Pafili and Mylonakis (2012) suggested that their father's occupation has an impact on teenagers' academic performance, whereas Heinla (2006) suggests that parents' profession influences students' creative thinking. On the contrary Karaiskos (2013) found that students' perceptions about health education are not affected by their parents' profession. In Cyprus, Nisiforou and Charalambides (2012) found that parents' occupation did not influence undergraduate university students' level of knowledge, attitudes and behavior towards biodiversity.

\section{Greek students' motivation towards science learning: existing data} According to the results of the international program Relevance of Science Education (ROSE) (Sjøberg \& Schreiner, 2010), Greek students seem to be highly motivated towards science in comparison to the other European countries that took part in the research. However, the PISA (OECD 2007) results attribute to Greek students' medium to low levels of scientific literacy and low levels of self-efficacy in science, which are connected to low levels of motivation to engage in science-related sectors in the future. Koumparou et al. (2009) recorded 259 Greek secondary students' views on biology, finding that students have a medium interest in biology 
that decreases as they progress to higher grades, a finding that is in accordance with those of Prokop, Prokop and Tunicliffe (2007) in Slovakian students.

In other countries one of the goals of secondary education is to enhance students' scientific literacy, with biology having a strong presence in the curriculum, but in Greece biology does not occupy the space it should (Mavrikaki, 2008).

\section{Research Questions and Hypotheses}

The research questions of the study are: 'Is SMTSL a valid and reliable instrument- with the proper adjustments substituting 'science' with 'biology' - to measure Greek students' motivation towards biology?', 'To what degree are Greek students motivated towards biology learning measured by adapted SMTBL' and 'Are there differences relating to students' gender and parents' occupation (relevant or not to biology) in students' motivation towards biology measured by adapted SMTBL?'

Therefore, our research hypotheses were stated as follows:

H1: The SMTSL are appropriate to measure Greek students' motivation towards biology learning.

H2: Greek students have medium motivation towards biology learning.

H3: Girls have the same motivation towards biology learning as boys.

H4: Students whose parents' occupation is relevant to biology (microbiologist, doctors, biology teachers etc.) have the same motivation towards biology learning as those whose parents' occupations are unrelated to biology.

\section{Data collection - Method}

\section{Participants}

The data were collected during January and February 2012. The questionnaire was administered to students attending public schools from various parts of Greece from diverse social and economic classes and rural and urban areas (schools in the prefecture of Attika, the city of Agrinio and the prefecture of Aitoloakarnania). Although it was a convenient sample (we chose students from schools that we could easily access) we made significant efforts to ensure that the sample would be as representative of the Greek student population as possible. 
We chose to administer the questionnaire to students of the $10^{\text {th }}$ grade $\left(1^{\text {st }}\right.$ high school year in the Greek Lyceum) as these are students that have already completed obligatory education in Greece (nine school years besides kindergarten) and they have chosen to continue their school studies. Students in $10^{\text {th }}$ grade are also the ones that take part in PISA.

The questionnaires were administered during biology class at school, by one of the authors who also was present during the whole time that students needed to answer it. We administered 380 questionnaires and we collected 360. The sample consisted of 178 (49.4\%) males and 182 females (50.6\%). 43 students from the sample (11.9\%) had at least one parent whose occupation was relevant to biology (doctors, nurses, biology teachers, specialists in environmental issues etc.).

\section{Instrument}

In order to adapt the SMTSL questionnaire so that it would assess Greek students' motivation towards biology learning we translated the original questionnaire into the Greek language, substituting the term 'science' with the term 'biology'. To avoid translation bias, two of the authors independently translated the questionnaire from English to Greek. Then they compared the two translations and adjusted them to produce a consensual questionnaire in Greek. Then, a Greek-English translator translated the Greek questionnaire into English and we compared this text to the original English questionnaire. We concluded in a $100 \%$ agreement that no significant additional changes were needed in order to match the original version; that the questionnaire as it was translated into Greek was the same as the original SMTSL (besides, of course, the substitution of the term 'science' with the term 'biology'). We then added questions about students' characteristics such as their gender or their parents' occupation. We will therefore call the instrument Students' Motivation Towards Biology Learning (SMTBL).

The questionnaire was a five-point Likert-type scale and respondents were asked to rate their agreement for each statement as follows: $1=$ strongly disagree, $2=$ disagree, $3=$ no opinion, $4=$ agree, and 5=strongly agree. Among the items of the questionnaire there were nine that were reverse items (items 2, 4, 5, 6, 7, 21, 22, 23 and 24). The data collected were analyzed using SPSS $^{\circledR}$ Statistics 19 software. Exploratory Factor Analysis (EFA) - Principal Components Analysis - was applied to the data to examine the construct validity of the instrument. Furthermore, since the sample had a normal distribution we used a two-tailed ttest to check for differences in motivation towards biology learning between male and female 
students and also between students with parents whose occupation was relevant or not to biology. We also used Pearson correlation to look for any correlations between the subscales of the SMTBL $(\mathrm{p}=0.05)$.

\section{Results}

\section{Reliability and construct validity of the instrument}

The SMTBL shows high internal consistency with Cronbach's alpha estimated to be $\alpha=0.88$. Exploratory Factor Analysis (EFA) was used to check for the construct validity of the instrument. This lead us to exclude the $6^{\text {th }}$ item 'During biology activities I prefer to ask other people for the answer than think for myself' as it did not give high loadings in any of the factors. The items 30 and 34 - 'I am willing to participate in the biology course because the content is exciting and changeable' and 'I am willing to participate in the biology course because it is challenging' - that in the original SMTSL questionnaire belonged to the Learning Environment Stimulation (LES) subscale in our study had very high loadings in the Biology Learning Value (BLV) subscale. We believe that these two items mostly refer to the content of biology and how challenging it is and how students value it, rather than to the learning environment. We therefore considered that these two items could be included in this subscale. Besides, as the creators of the SMTSL questionnaire state (Tuan, Chin \& Shieh, 2005: 648) '...scales such as learning environment stimulation and science learning value contribute more on attitude towards science than to students' motivation toward science learning'.

Thus, the SMTBL consists of 34 - instead of 35 - items distributed in six subscales. The data collected from the 360 Greek students were analyzed by means of Principal Components Analysis. The KMO measure of sampling adequacy was 0.86 indicating that the sample size is adequate for factorial analysis (Hutcheson \& Sofroniou 1999). The strength of the relationship among the 34 variables (items) was high, as Bartlett's test of sphericity produced a value of 3930.10 with a significance level <.001 indicating the appropriateness of the factor analysis for the data, something that was also implied by the size of the sample (Tabachnick \& Fidell, 2007). 
Varimax rotation was applied and the 34 items of the SMTBL gave medium to very high loadings to 6 independent factors - from the whole 34 loadings only three were less than 0.50 - that interpreted the $52.6 \%$ of total variance of results. Factor structures and loadings of the 34 items in SMTBL questionnaire are presented in Table 1 and the item loadings and the percentage of variance that each factor explains are presented in Table 2.

Table 1. Factor Loading of Items in the SMTBL Questionnaire and the Percentage of Variance explained by each Factor $(n=360) *$

\begin{tabular}{|c|c|c|c|c|c|c|}
\hline & Factor 1 & Factor 2 & Factor 3 & Factor 4 & Factor 5 & Factor 6 \\
\hline & $12.2 \%$ & $9.9 \%$ & $8.5 \%$ & $7.8 \%$ & $7.7 \%$ & $6.5 \%$ \\
\hline$\overline{\text { BLV6 (LES1) }}$ & .738 & & & & & \\
\hline BLV7 (LES5) & .731 & & & & & \\
\hline BLV2 & .649 & & & & & \\
\hline BLV3 & ,623 & & & & & \\
\hline BLV1 & .618 & & & & & \\
\hline BLV4 & .613 & & & & & \\
\hline BLV5 & .608 & & & & & \\
\hline$\overline{\text { ALS8 }}$ & & .699 & & & & \\
\hline ALS 5 & & .666 & & & & \\
\hline ALS 6 & & .587 & & & & \\
\hline ALS 4 & & .568 & & & & \\
\hline ALS 3 & & .553 & & & & \\
\hline ALS 1 & & .552 & & & & \\
\hline ALS 7 & & .500 & & & & \\
\hline ALS 2 & & .377 & & & & \\
\hline$\overline{\text { SE2 }}$ & & & .700 & & & \\
\hline SE3 & & & .682 & & & \\
\hline SE4 & & & .666 & & & \\
\hline SE1 & & & .569 & & & \\
\hline SE5 & & & .556 & & & \\
\hline SE7 & & & .458 & & & \\
\hline$\overline{\mathrm{PG} 2}$ & & & & .856 & & \\
\hline PG3 & & & & .824 & & \\
\hline PG4 & & & & .760 & & \\
\hline PG1 & & & & .523 & & \\
\hline AG4 & & & & & .736 & \\
\hline AG3 & & & & & .687 & \\
\hline AG2 & & & & & .656 & \\
\hline AG1 & & & & & .639 & \\
\hline AG5 & & & & & .592 & \\
\hline$\overline{\text { LES3 }}$ & & & & & & .727 \\
\hline LES4 & & & & & & .699 \\
\hline LES2 & & & & & & .613 \\
\hline LES6 & & & & & & .469 \\
\hline
\end{tabular}

*Loadings smaller than 0.3 have been omitted. 
Table 2. The Items of each Subscale of the SMTBL and the Percentage of Total Variance explained

\begin{tabular}{|c|c|c|}
\hline Subscale(\#items) & $\begin{array}{l}\text { Percent of } \\
\text { total variance } \\
\text { explained }\end{array}$ & Items \\
\hline $\begin{array}{l}\text { Biology } \\
\text { Learning Value } \\
(B L V) \\
\text { (7) }\end{array}$ & 12.2 & $\begin{array}{l}\text { I think that learning biology is important because I can use it in my everyday } \\
\text { life. } \\
\text { I think that learning biology is important because it stimulates thought. } \\
\text { I think that it is important for me to learn to solve problems in biology. } \\
\text { I think that it is important for me to participate in investigative activities in } \\
\text { biology. } \\
\text { It's important for me to have the opportunity to satisfy my curiosity when } \\
\text { learning biology. } \\
\text { I want to take part in biology lessons because the course content is } \\
\text { interesting and changeable. } \\
\text { I want to take part in biology lessons because they are very interesting. }\end{array}$ \\
\hline $\begin{array}{l}\text { Active Learning } \\
\text { Strategies (ALS) } \\
\text { (8) }\end{array}$ & 9.9 & $\begin{array}{l}\text { When I learn about new concepts in biology, I connect them with my } \\
\text { previous experiences. } \\
\text { If I don't understand a concept in biology, I seek out relevant sources on } \\
\text { information to help me. } \\
\text { If I don't understand a concept in biology, I talk about it with my teacher or } \\
\text { with classmates in order to understand it better. } \\
\text { During biology lessons, I try to make connections between the concepts I } \\
\text { learn. } \\
\text { When I make a mistake in biology, I try to understand why. } \\
\text { When I come across concepts in biology that I don't understand, I try to learn } \\
\text { them anyway. } \\
\text { When new concepts in biology contradict my previous knowledge, I try to } \\
\text { understand why. }\end{array}$ \\
\hline $\begin{array}{l}\text { Self-efficacy } \\
(S E) \\
(6)\end{array}$ & 8.5 & $\begin{array}{l}\text { I am sure that I can understand the biology course content, both easy and } \\
\text { difficult. } \\
\text { I am not sure that I can understand difficult concepts in biology. } \\
\text { I am sure that I can do well in a biology test. } \\
\text { However hard I try, I can't learn biology. } \\
\text { If a biology assignment is too difficult, I abandon it or only do the easy parts. } \\
\text { During biology assignments, I prefer to ask others for the answers rather } \\
\text { than think for myself. } \\
\text { When I find studying for biology class difficult, I don't try to learn. }\end{array}$ \\
\hline $\begin{array}{l}\text { Performance } \\
\text { Goal }(P G) \\
\text { (4) }\end{array}$ & 7.8 & $\begin{array}{l}\text { I participate in biology lessons to get a good grade. } \\
\text { I participate in biology lessons to look better than other students. } \\
\text { I participate in biology lessons so that other students will see me as smart. } \\
\text { I participate in biology lessons so that the teacher will give me attention. }\end{array}$ \\
\hline $\begin{array}{l}\text { Achievement } \\
\text { Goal }(A G) \\
\text { (5) }\end{array}$ & 7.7 & $\begin{array}{l}\text { In a biology lesson I feel more satisfied when I get a good grade on a test. } \\
\text { I feel more satisfied when I'm sure about the subject of a biology class. } \\
\text { In a biology lesson I feel more satisfied when I can solve a difficult problem. } \\
\text { In a biology lesson I feel more satisfied when the teacher accepts my ideas. } \\
\text { In a biology lesson I feel more satisfied when other students accept my } \\
\text { ideas. }\end{array}$ \\
\hline $\begin{array}{l}\text { Learning } \\
\text { Environment } \\
\text { Stimulation } \\
(\text { LES) } \\
(4)\end{array}$ & 6.5 & $\begin{array}{l}\text { I want to participate in biology lessons because the teacher uses a variety of } \\
\text { teaching methods. } \\
\text { I want to participate in biology lessons because the teacher doesn't pressure } \\
\text { me. } \\
\text { I want to participate in biology lessons because the teacher gives me } \\
\text { attention. } \\
\text { I want to take biology lessons because students participate in discussions. }\end{array}$ \\
\hline
\end{tabular}




\section{Reliability and discriminant validity of the emerged factors}

The internal consistencies of the six subscales of the SMTBL were estimated to be generally satisfactory since Cronbach's alphas ranged between 0.67 and 0.86 (Table 3). The discriminant validity of each subscale - 'the extension to which each subscale measured a dimension different from that measured by any other scale' (Tuan, Chin, \& Shieh, 2005:646) ranged from 0.14 to 0.38 , showing the independence of each subscale (Hair, Anderson, Tatham, \& Black, 1998). All the subscales were significantly correlated $(p<.05)$ except for the subscales $B L V$ and $P G$ which were not correlated ( $p>.05)$.

Table 3. The Internal Consistency (Cronbach's alpha) of the SMTBL Questionnaire and its Subscales and their Discriminant Validity

\begin{tabular}{lcccc}
\hline Scale/subscale & Items & Mean (SD) & $\begin{array}{c}\text { Cronbach's } \\
\text { alpha }\end{array}$ & $\begin{array}{c}\text { Mean (SD) of } \\
\text { the } \\
\text { correlations } \\
\text { with the other } \\
\text { subscales }\end{array}$ \\
\hline Self-efficacy (SE) & 6 & $3.45(0.69)$ & 0.75 & $0.32(0.19)$ \\
Active learning strategies (ALS) & 8 & $3.61(0.60)$ & 0.79 & $0.36(0.21)$ \\
Biology learning value (BLV) & 7 & $3.58(0.78)$ & 0.86 & $0.38(0.21)$ \\
Performance goal (PG) & 4 & $3.50(0.84)$ & 0.76 & $0.14(0.06)$ \\
Achievement goal (AG) & 5 & $3.75(0.66)$ & 0.73 & $0.24(0.05)$ \\
Learning Environment Stimulation & 4 & $3.15(0.75)$ & 0.67 & $0.27(0.09)$ \\
(LES) & & & & \\
\hline SMTBL & 34 & $3.54(0.45)$ & 0.87 & \\
\hline
\end{tabular}

Greek students' motivation towards biology was estimated based on the means of their scores for each subscale and for the whole questionnaire. We followed Cavaş's (2011) classification system according to which a high level of motivation included means between 4.41 and 5.00, a medium level of motivation included means between 4.40 and 3.39 and a low level of motivation included means lower than 3.38. Therefore, according to the results presented in Table 3 Greek students have medium motivation toward biology learning since their mean score was 3.54 and their mean scores in each subscale were considered medium except for the Learning Environment Stimulation scale where their motivation was low (3.15<3.38), still following the Cavaş's (2011) classification.

A two-tailed t-test revealed that there were no statistically significant differences in the overall SMTBL between male and female students. Regarding the subscales, girls have 
greater scores in Performance Goal $(M=3.60, S E=0.06)$ than boys $(M=3.39, S E=0.06)$. This difference was significant $\left(t_{(347)}=-2.41, p<.05\right)$, however it represented a low sized effect $r=.13$

Table 4. Means of Greek Students' Scores in the SMTBL and the Six Subscales according to their Gender

\begin{tabular}{lcccc}
\hline Scale & Gender & Mean & $\begin{array}{c}\text { Standard } \\
\text { deviation }\end{array}$ & $\mathrm{p}$ \\
\hline SE & Male & 3.48 & 0.68 & .423 \\
& Female & 3.42 & 0.69 & .238 \\
\hline ALS & Male & 3.58 & 0.64 & .073 \\
& Female & 3.66 & 0.56 & $.016^{*}$ \\
\hline BLVI & Male & 3.50 & 0.81 & .348 \\
& Female & 3.65 & 0.73 & .959 \\
\hline PG & Male & 3.39 & 0.85 & .098 \\
& Female & 3.60 & 0.82 & \\
\hline LES & Male & 3.72 & 0.72 & 0.60 \\
& Female & 3.79 & 0.74 & \\
\hline SMTBL & Male & 3.15 & 0.77 & \\
& Female & 3.16 & 0.38 & \\
\hline
\end{tabular}

*Statistically significant $(p<.05)$

Parents' occupation did not differentiate significantly in the SMTBL total or in any of the six subscales $(\mathrm{p}>.05)$.

\section{Discussion}

In Greece, there is scarce of studies on students' motivation towards biology learning. Dermitzaki et al. (2012) have adapted the SMTSL to Greek for physics and have gathered data from Greek university students. The main goals of this study were to adapt the SMTSL to the Greek language focusing on biology learning (SMTBL), to measure Greek $10^{\text {th }}$ grade students' motivation towards biology learning and to examine whether students' gender and their parents' occupation play a role.

The internal consistency of the SMTBL was high and an Exploratory Factor Analysis (EFA) resulted in the six factors originally proposed by Tuan, Chin and Shieh (2005) with some adjustments: one item $\left(6^{\text {th }}\right.$ in the SMTSL- 'during biology activities, I prefer to ask other people for the answer rather than think for myself'-) was eliminated for not loading high in any of the six factors and items 30 'I am willing to participate in this science course because the content is exciting and changeable' and 34 'I am willing to participate in this 
science course because it is challenging' that originally constituted the Learning Environment Stimulation subscale of the SMTSL (Tuan, Chin, \& Shieh, 2005) in our research contributed to the factor Biology Learning Value $(B L V)$. This change led to an increase of the internal consistency of the subscale $B L V$ from $\alpha_{\mathrm{BLV}}=0.52$ in Dertmitzaki et al. (2012) to $\alpha_{\mathrm{BLV}}=0.86$ in our study, which could be explained by the increase by two of the number of items in the $B L V$ subscale; however, this was not followed by a relevant drop to the internal consistency of the subscale $L E S-\alpha_{(\mathrm{LES})}=0.67$ in our study and $\alpha_{(\mathrm{LES})}=0.68$ in Dermitzaki et al. (2012) study. We believe that a good explanation would be that the wording of these two items was such that could be interpreted as attributing a learning value to biology therefore they should belong to this subscale. Therefore, there were no major differences with the original instrument and we support Tuan, Chin and Shieh (2005) and Dermitzaki et al. (2012) in their suggestion that there are six factors that shape students' motivation towards science (biology in our research): self-efficacy, biology learning value, performance goal, achievement goal, active learning strategies and learning environment stimulation. These results support our first research hypothesis that the SMTBL resulting from the appropriate adaptation of the SMTSL could be used to assess Greek students' motivation toward biology learning.

The levels of Greek $10^{\text {th }}$ grade students' motivation towards biology learning were assessed as medium, therefore leading us to accept the second research hypothesis. The medium levels of motivation could be attributed to the few hours of biology in Greek schools (Mavrikaki, 2008) and in the use of unattractive teaching methods by the teachers. In research by Koumparou et al. (2012) into students' knowledge and attitudes towards biology and its applications these were assessed as medium to positive, results that may be connected to the motivation levels we observed in the present research, as students' motivation is significantly correlated to students' attitudes toward science and their achievement levels (Tuan, Chin, \& Shieh, 2005).

Greek students show medium levels of motivation in all motivation factors, with the factor 'Learning Environment Stimulation' motivating them less than any other factor.

The analysis of students' scores in each factor that contributed to students' motivation revealed that Greek students have medium to positive self-efficacy scores in contrast to the PISA 2006 results (OECD, 2007), that showed that Greek high school students have low levels of self-efficacy. Maybe in the six years that have passed the PISA results were important in shaping better self-efficacy in students. In these six years there have been some 
changes to the content of biology courses in grades 7 to 9 . New textbooks have been introduced to schools (Mavrikaki, Gouvra, \& Kampouri 2007a, 2007b) which we believe are 'friendlier' to students, but more research should be done to give us results to support this claim.

In our research we found no statistically significant differences between male and female students' overall motivation towards biology, thereby confirming the third research hypothesis. In a previous study (Andressa, Gkagkavouzis, Tsilivi, \& Mavrikaki, 2011) we found that Greek high school male and female students differed neither in their biology knowledge nor in their attitudes towards biological applications. These findings confirm the results of the present study, given that attitudes are not irrelevant to motivation. Other researchers (Baram-Tsabari, Sethi, Bry, \& Yarden, 2010; Ekici, 2010; Trumper, 2006) suggest that there are statistically significant differences between male and female students' motivation, with girls being more motivated than boys towards biology. We did not make such findings in our research. The only differences recorded between Greek male and female students in our sample were those regarding their performance goal motivation. Female students are more motivated to perform better, thus confirming the results of Sevinç, Özmen and Yiğit (2011) regarding Turkish students and contradicting the results of Koul, Lerdpornkulrat and Chantara (2011) regarding Thai students. According to the latter, Thai boys were more focused on performing better, in order to impress others and to gain others' recognition. This difference between the two genders in Thailand which was not found in Greece could be explained by the difference in social conditions in the two countries: in Thailand gender roles are highly predetermined and it is possible that the female stereotype of being less competitive would discourage girls from endorsing performance goals. However, it is noteworthy that Turkey gave results that were more similar to Greece than to Thailand, as in Turkey males are more competitive than females (Blocker \& Eckberg 1997). Therefore, we believe that the differences among these three countries should be attributed to differences in their educational systems. Further research on cross-cultural differences on students' motivation would give us more data to support these claims.

Parents' occupation did not have a statistically significant impact on Greek students' motivation towards biology learning, leading us to confirm the fourth research hypothesis (H4). The findings of other researchers that examined the effects of parents' educational level on students' motivation towards science were relevant (Sevinç, Özmen, \& Yiğit, 2011). 


\section{Implications for future research}

Research on students' motivation seems to be essential for the context of learning and teaching in most countries. However, in Greece there are no relevant data, only data showing the low knowledge levels of Greek students. It would be interesting to study whether students' motivation towards biology changes during a school year. Research has proven that students' motivation towards science is affected by the degree of their active involvement in the learning process (Mamlok-Naaman, 2011). If students begin the school year having low motivation towards biology, then to what extent could certain teaching strategies in biology change their motivation?

We also suggest that more independent variables should be assessed on whether they play a role in students' motivation towards biology such as whether students attend home based private lessons or laboratory classes. It would also be interesting to study pre-service teachers' motivation towards biology who themselves will be called to motivate their students towards biology learning.

\section{References}

Ainley, M. (2004, November). What do we know about student motivation and engagement. Paper presented at the annual meeting of the Australian Association for Research in Education, Melbourne, VIC.

Andressa, H., Gkagkavouzis, K., Tsilivi, \& Mavrikaki, E. (2012). Greek high school students' biological science knowledge and their attitudes about biotechnology and biological applications. Paper presented at the Conference «New Perspectives in science Education) (Retrieved 15 June, from http://www.pixel-online.net/science/VP_SSE08.php).

Araoye, M.I. (2013). Redressing Students' Motivation and Academic Achievement in Biology Education at the Federal College of Education (Special) Oyo. (Accessed August 22, from http://conference.pixel-online.net/npse2013/common/download/Paper_pdf/071-ESM01-FPAraoye-NPSE2013.pdf)

Barak, M., Ashkar, T., \& Dori, Y. J. (2011). Learning Science via animated movies: Its effect on students' thinking and motivation. Computers \& Education, 56(3), 839-46. Doi:10.1016/j.compedu.2010.10.025.

Baram-Tsabary, A., Sethi, R.J., Bry, L., \& Yarden, A. (2010). Identifying Students' Interests in Biology Using a Decade of Self-Generated Questions. Eurasia Journal of Mathematics, Science \& Technology Education, 6(1), 63-75.

Baser, M. (2007). The contribution of learning motivation, reasoning ability and learning orientation to ninth grade international baccalaureate and national program students' understanding of mitosis and meiosis. Unpublished master's thesis, Ankara, Turkey: Middle East Technical University.

Blocker, T. J., \& Eckberg, D. L. (1989). Environmental Issues as Women's Issues: General Concerns and Local Hazards. Social Science Quarterly, 70, 586-593.

Cavaş, P. (2011). Factors affecting the motivation of Turkish primary students for Science learning. Science Education International, 22(1), 31-42.

Dawson, C. (2000). Upper primary boys' and girls' interests in Science: have they changed since 1980 ? International Journal of Science Education, 22(6), 557-570. 
Dermitzaki, I., Stavroussi, P., Vavougios, D., \& Kotsis, K.T. (2012). Adaptation of the Students' Motivation Towards Science Learning (SMTSL) questionnaire in the Greek language. European Journal of Psychology Education, 28, 747-766. DOI 10.1007/s10212-012-0138-1.

Ekici, G. (2010). Factors affecting biology lesson motivation of high school students. Procedia Social and Behavioral Sciences, 2, 2137-2142.

Glynn, S.M., Brickman, P., Armstrong, N., \& Taasoobshirazi, G. (2011). Science Motivation Questionnaire II: Validation with Science Majors and Nonscience Majors. Journal of Research in Science Teaching, 48(10), 1159-1176.

Glynn, S.M., Taasoobshirazi, G., \& Brickman, P. (2009). Science Motivation Questionnaire: Construct Validation with Nonscience Majors. Journal of Research in Science Teaching, 46(2), 127-146.

Hair, J. F., Anderson, R. E., R. L. Tatham, R.L., \& Black, W. C. (1998). Multivariate Data Analysis with Readings (5th ed.). Englewood Cliffs, NJ: Prentice Hall.

Heinla, E. (2006). Creative thinking of adolescents in Estonian society. Young, 14, 235-255. Doi: $10.1177 / 1103308806065818$.

Hutcheson, G., \& Sofroniou, N. (1999). The multivariate social scientist: Introductory statistics using generalized linear models. Thousand Oaks, CA: Sage Publications.

Karaiskos, D. (2013). Students' perceptions about Health Education. Unpublished master's thesis, Korinthos, Greece: University of Peloponnese.

Keeves, J., \& Kotte, D. (1992). Disparities between the sexes in Science Education 1970-84. In J. Keeves (ed.), The IEA Study of Science III: Changes in Science Education and Achievement 1970-1984, (pp. 141-164). Elmsford, NY: Pergamon.

Koul, R., Lerdpornkulrat, T., \& Chantara, S. (2011). Relationship between Career Aspirations and Measures of Motivation Toward Biology and Physics, and the Influence of Gender. Journal of Science Education and Technology, 20, 761-770.

Koumparou, H., Kyriakoudi, M., Lykouras, F., Economou, S., Papacharalampous, I., Soule, I.

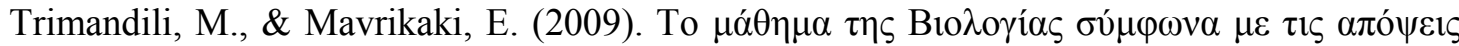

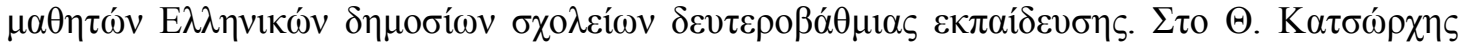

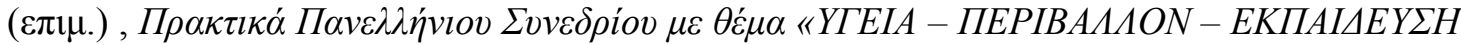

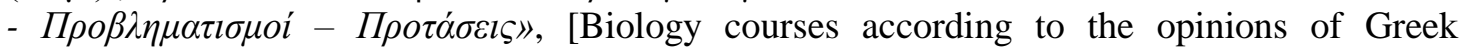
secondary education students of public schools. In Th. Katsorchis (ed.), Proceedings of the PanHellenic Conference "Health-Environment-Education: Problems and Proposals"]. (pp. 68-76). Athens: University of Athens.

Koumparou, H., Kyriakoudi, M., Papacharalampous, I., Trimandili, M., \& Mavrikaki, E. (2012). Greek secondary school students' views about biology. International Journal of Environmental and Science Education, 7(2): 217-232.

Krogh, L. B., \& Thomsen, P. V. (2005). Studying students' attitudes towards science from a cultural perspective but with a quantitative methodology: border crossing into the physics classroom. International Journal of Science Education, 27(3), 281-302. Doi:10.1080/09500690412331314469.

Linnenbrink, E. A., \& Pintrich, P. R. (2002). Motivation as an enabler for academic success. School Psychology Review, 31, 313-327.

Mamlok-Naaman, R. (2011). How can we motivate high school students to study science? Science Education International, 22, 5-17.

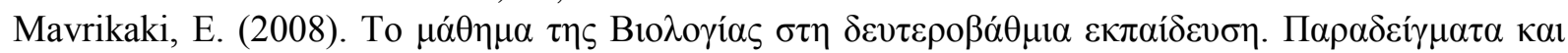

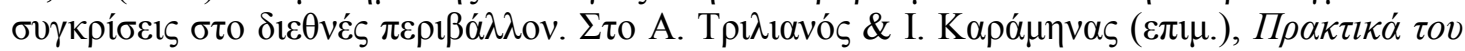

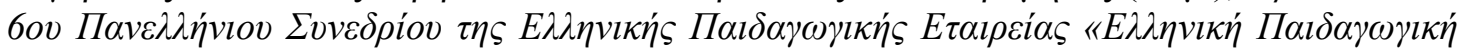

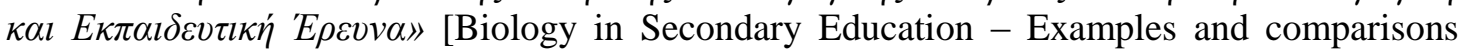
from international education systems. In A. Trilianos \& I. Karaminas (Eds.), Proceedings of the $6^{\text {th }}$ PanHellenic Conference of the Greek Pedagogical Society "Greek Pedagogical and Educational Research"], (pp. 1165-1171). Athens: Atrapos.

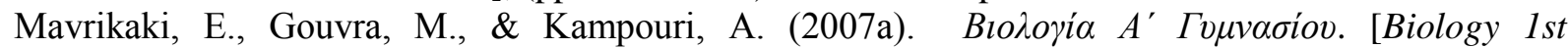
Gymnasium]. Athens: Patakis \& Paedagogical Institute. (in Greek). 


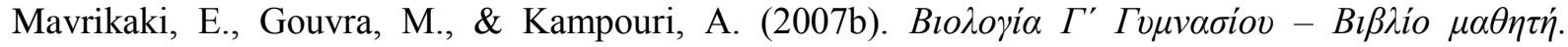
[Biology 3rd Gymnasium]. Athens: Patakis \& Paedagogical Institute. (in Greek).

Mavrikaki, E., Koumparou, H., Kyriakoudi, M., Papacharalampous, I., \& Trimandili, M., (2012). Greek secondary school students' views about biology. International Journal of Environmental and Science Educatio, 7(2), 217-232.

Nisiforou, O., \& Charalambides, A.G. (2012). Assessing Undergraduate University Students' Level of Knowledge, Attitudes and Behaviour Towards Biodiversity: A case study in Cyprus. International Journal of Science Education, 34(7), 1027-1051. Doi:10.1080/09500693.2011.637991.

OECD (Organisation for Economic Cooperation and Development) (2007). Programme for International Student Assessment (PISA) 2006: Science Competencies for Tomorrow's World Executive Summary. OECD.

Pafili, E., \& Mylonakis, J. (2012). A Demographic Presentation of the Relationship between Parents' Profession and Children's Education in Remote Small Islands in the Aegean Sea: A Developmental Approach. Journal of Sustainable Development, 5(6). Retrieved June 15 from http://dx.doi.org/10.5539/jsd.v5n6p113.

Palmer, D. (2005). A Motivational View of Constructivist-informed Teaching. International Journal of Science Education, 27(15), 1853-1881.

Prokop, P., Prokop, M., \& Tunnicliffe, S. (2007). Is biology boring? Student attitudes toward biology. Journal of Biological Education, 42(1), 36-39.

Prokop, P., Tuncer, G., \& Chudá, J. (2007). Slovakian Students' Attitudes toward Biology. Eurasia Journal of Mathematics, Science \& Technology Education, 3(4), 287-295.

Sevinç, B., Özmen, H., \& Yiğit, N. (2011). Investigation of primary students' motivation levels towards science learning. Science Education International, 3, 218-232.

Shihusa , H., \& Keraro, F.N. (2009). Using Advance Organizers to Enhance Students' Motivation in Learning Biology. Eurasia Journal of Mathematics, Science \& Technology Education, 5(4), 413-420.

Sjøberg, S., \& Schreiner, C. (2010, March). The ROSE project: An overview and key findings. University of Oslo. (Retrieved June 3, from http://roseproject.no/network/countries/norway/eng/nor-Sjoberg-Schreiner-overview2010.pdf).

Tabachnick, B.G., \& Fidell, L.S. (2007). Using multivariate statistics. Boston: Pearson/Allyn \& Bacon.

Trumper, R. (2006). Factors Affecting Junior High School Students' Interest in Biology. Science Education International, 17, 31-48.

Tuan, H.L., Chin C.C., \& Shieh S.H. (2005). The development of a questionnaire to measure students' motivation towards science learning. International Journal of Science Education, 6, 639-654.

Tuan, H.L., Chin, C.C., \& Tsai, C.C. (2003). Promoting Students' Motivation in Learning Physical Science - An Action Research Approach. Paper presented at the National Association for Research in science Teaching, Philadelphia.

Velayutham, S., Aldridge, J., \& Fraser, B. (2011). Development and Validation of an Instrument to Measure Students' Motivation and Self-Regulation in Science Learning. International Journal of Science Education, 33(15), 2159-2179.

Wigfield, A., Battle, A., Keller, L.B., \& Eccles, J.S. (2002). Sex differences in motivation, selfconcept, career aspiration, and career choice: implications for cognitive development. In A. McGillicuddy-De Lisi \& R. De Lisi (Eds.), Biology, Society, and Behavior: the development of sex differences in cognition (pp. 93-124). Westport, CT: Ablex.

Zeyer, A. (2010). Motivation to Learn science and Cognitive Style. Journal of Mathematics, Science and Technology Education, 6(2), 121-128. 